\title{
Mapping the implementation process for subsidized fertilizer distribution under Ghana's Planting for Food and Jobs Program
}

Noora-Lisa Aberman, Doreen S. Kufoalor, and Rachel Gilbert 


\section{TABLE OF CONTENTS}

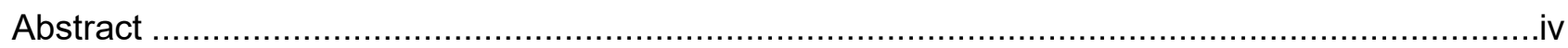

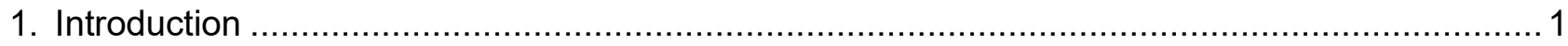

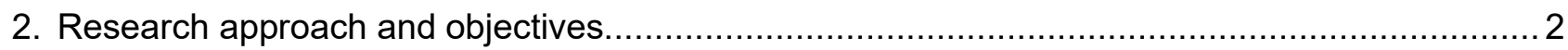

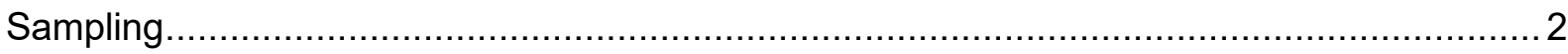

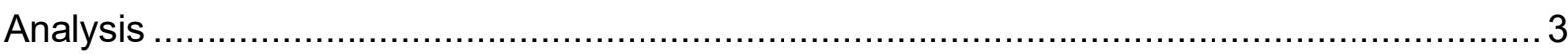

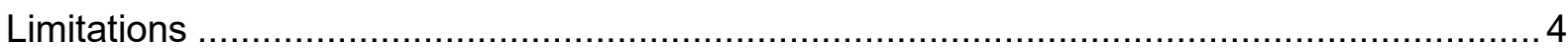

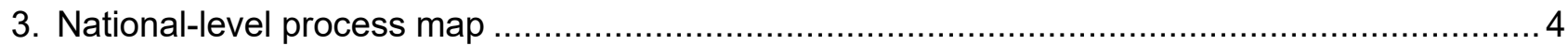

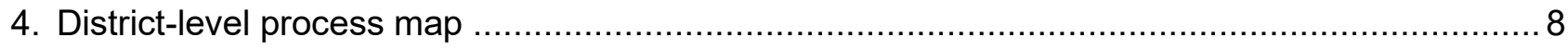

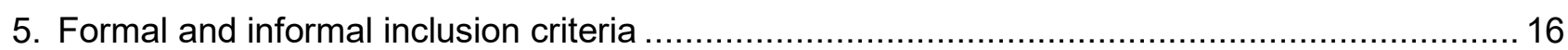

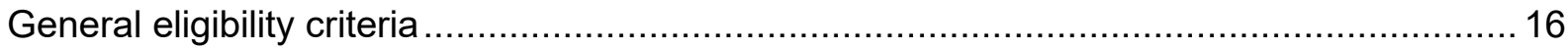

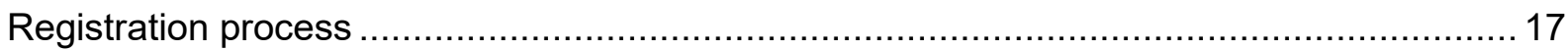

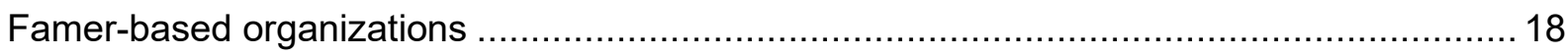

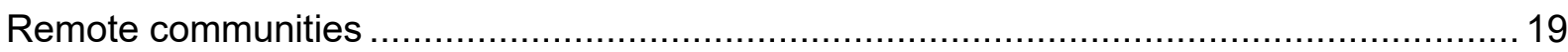

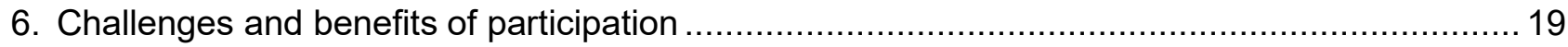

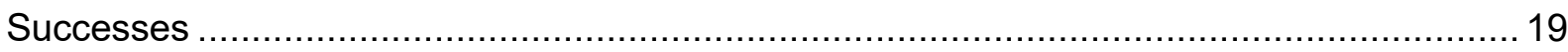

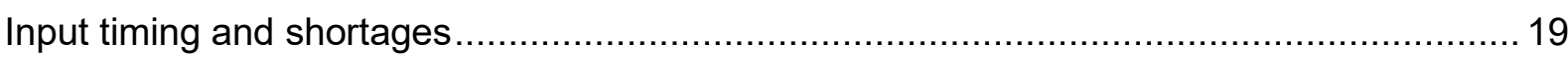

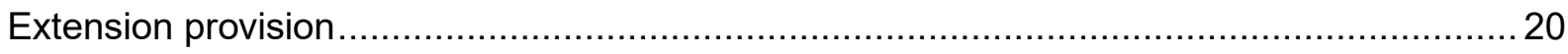

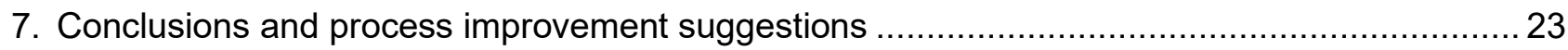

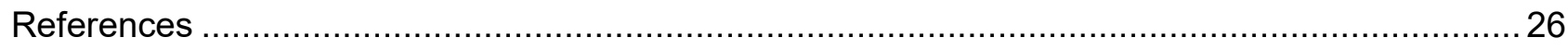

\section{LIST OF TABLES}

Table 1. Sample for district key informant interviews and in-depth interviews with farmers 3

Table 2. Key challenges to participation in the Planting for Food and Jobs Program - illustrative quotes from both participants and non-participants

Table 3. Key benefits to participating in the Planting for Food and Jobs Program - illustrative quotes from beneficiary farmers

\section{LIST OF FIGURES}

Figure 1. Key directorates of the Ministry of Food and Agriculture involved in the Planting for Food and Jobs Program

Figure 2. Process Net-Map of district-level Planting for Food and Jobs Program activities and actors 


\section{ACRONYMS AND ABBREVIATIONS}
AEA
Agriculture Extension Agent
DCE/MCE District Chief Executive or Municipal Chief Executive
DCS
Directorate of Crop Services, MoFA
DD
District Director of MoFA
M\&E
Monitoring and Evaluation
MIS
Management and Information Systems
MoFA
Ministry of Food and Agriculture
NABCO Nation Builder's Corps
PFJ Planting for Food and Jobs program
PFJDO Planting for Food and Jobs Desk officer
PPMED Policy Planning Monitoring and Evaluation Directorate, MoFA
PPRSD Plant Protection and Regulatory Services Directorate, MoFA 


\section{ABSTRACT}

Planting for Food and Jobs (PFJ) is Ghana's flagship program for agricultural transformation and employment creation. Alongside other components, the program provides subsidized fertilizer, hybrid and open-pollinated seeds and other planting materials, improved extension services, and marketing support to smallholder farmers across the country. The objective of this study was to assess the implementation process of the PFJ input subsidy program in order to identify opportunities for strengthening the process. The study focused only on fertilizer distribution as a distinct complex process of importance, although some of the lessons will be applicable to other components of the PFJ program. The study applied the Process Net-Map method, a research approach that is particularly useful for assessing the coherence between formally prescribed procedures and how those procedures are implemented in practice, enabling the identification of inefficiencies and bottlenecks in a complex process.

The implementation of the PFJ fertilizer subsidy program was mapped in interviews with key informants at national level and in six districts. Interviews with national-level stakeholders yielded important insights about the complex largely administrative process involved in the implementation of PFJ, which is generally unseen by beneficiaries. These administrative processes, however, have a considerable impact on the timeliness of the program and provide an outline of the intended implementation process at the local district level. The perspectives of farmers with regards to these processes were also investigated through in-depth interviews. Across the study districts we found some ambiguity and inconsistency in following the formally prescribed procedures for implementing the PFJ fertilizer subsidy program.

While we found broad agreement among key informants and farmers that the program is meeting its objectives, some areas in which the implementation process for the PFJ fertilizer subsidy program could be improved are highlighted. These improvements will enhance the efficiency and impact of the program. 


\section{INTRODUCTION}

Planting for Food and Jobs (PFJ) is Ghana's flagship program for agricultural transformation and employment creation in the country. Through the provision of subsidized fertilizer, hybrid and open-pollinated seeds and other planting materials, improved extension services, and marketing support to smallholder farmers across the country, the program aims to increase food production of priority crops, such as maize, rice, sorghum, soyabean, cassava, and vegetables, and to provide employment opportunities within and outside of the agricultural sector. The main objective of the PFJ program is to encourage farmers to increase crop productivity and incomes through access to both input and output markets. As a national agricultural program, the PFJ intervention has the potential to boost Ghana's productivity, to reduce food shortages, and to reduce imports of basic food crops (Mabe, Danso-Abbeam, and Ehiakpor, 2018). Following a pilot in 2017 with 200,000 direct beneficiary farmers, PFJ was scaled up in 2018 to 500,000 beneficiaries, while a target of reaching 1.5 million farmers by 2020. The Government of Ghana plans to invest more than USD 650 million over the four implementation years from 2017 to 2020 .

Key features of the PFJ program in 2019 included:

- 50 percent subsidy on seeds and fertilizer

- Free insecticides to help fight the fall army worm

- Access to inputs for application on up to 2 hectares of cropland

- Prioritization of specific crops - initially in 2017 maize, rice, soyabean, sorghum, and vegetables were the focus crops. Groundnut, cassava, cowpea, and orange fleshed sweet potatoes were added in 2018 and 2019.

The objective of this study is to assess the quality of the process of implementation of the PFJ input subsidy program in order to identify opportunities for strengthening the process. Weaknesses and inefficiencies in the process are important to identify because they can diminish any positive impacts of the program for beneficiaries. Because seed and fertilizer entail separate procurement and distribution processes, we focused only on fertilizer distribution. However, some of the lessons will be applicable to all subsidized input provisioning under PFJ. A useful follow-up to this study could focus on the seed distribution process. Our analyses in this paper focus on the implementation of the fertilizer component of the PFJ input subsidy program at national and district levels - we did not explicitly analyze the role of regional government actors.

This paper is organized as follows: First, we briefly describe the research approach, sampling procedures, and analysis. Then we present the actors involved and map at the national level the PFJ fertilizer subsidy implementation process. Next, we present the district implementation process maps and actors involved. This section emphasizes implementation challenges and discrepancies in implementation across districts in comparison to the plans at national level, as well as benefits and challenges of the program expressed by beneficiary farmers. This is followed by two discussion sections detailing key issues raised by key informants and beneficiary farmers, including targeting procedures, benefits of the program, and challenges to participation. Finally, we summarize the key insights from the analysis and the program design modifications to which they point. 


\section{RESEARCH APPROACH AND OBJECTIVES}

In order to assess the implementation process for subsidized fertilizer distribution under PFJ, we apply the Process Net-Map method to map the steps in the process, institutions, and individuals involved, administrative requirements, and timing (Birner, Cohen, and llukor 2011). We then consider any challenges that arise at each step in the process. Process NetMap was developed to assess the coherence between formally prescribed procedures, on the one hand, and procedures in practice, on the other. In this case, we begin with nationallevel process maps to identify the intended implementation process. Next, the implementation processes from six selected districts are described and assessed relative to the national-level process. Differences across districts are also considered. Using this approach, we highlight variations in implementation of the PFJ fertilizer subsidy program across districts, the challenges or benefits associated with these variations, and the opportunities for strengthening operational efficiency and overall effectiveness of the program.

Key informants involved in the program implementation at national and district levels participated in participatory interviews wherein they visualized and sketched with pen and paper the steps in the program implementation process while describing the details and challenges associated with each step. In addition, both program beneficiary farmers and non-beneficiary farmers were interviewed to explore their understanding of the process for receiving subsidized fertilizer. These interviews assessed their understanding of the program requirements, highlighting any challenges encountered and benefits experienced. The farmer interviews were piloted in January and March of 2020. Due to COVID-19 pandemic related delays, interviews were finally conducted between July and August 2020. In total 38 key informant interviews and 128 in-depth farmer interviews ( 77 beneficiaries and 51 nonbeneficiaries) were conducted. All interview questions were related specifically to the 2019 agricultural season, which was the previous cropping season at the time the interviews were conducted.

\section{Sampling}

A multi-stage stratified sampling approach was adopted. The first stage involved the purposive selection of six districts within three agro-ecological zones of Ghana: namely, the Southern, Middle-Belt, and Northern zones. Each district can be considered a unique case and was chosen based on its unique characteristics and cropping patterns. We also sought in our choice of study districts to capture all of the focus crops receiving PFJ input support (Goodrick 2014). Two districts were selected from each of the three zones (Table 1). The names of the districts are not included in the report to ensure the confidentiality of respondents. To further protect identities, we refer to the region within which the district is located rather than the district itself. 
Table 1. Sample for district key informant interviews and in-depth interviews with farmers

\begin{tabular}{|c|c|c|c|c|c|c|}
\hline \multirow[b]{3}{*}{ Zone } & \multirow[b]{3}{*}{ Region } & \multirow{3}{*}{$\begin{array}{c}\text { Key } \\
\text { informant } \\
\text { interviews, } \\
\mathbf{n}\end{array}$} & \multicolumn{4}{|c|}{ In-depth Interviews } \\
\hline & & & \multicolumn{2}{|c|}{ Beneficiary } & \multicolumn{2}{|c|}{$\begin{array}{c}\text { Non- } \\
\text { Beneficiary }\end{array}$} \\
\hline & & & Sex & n & Sex & n \\
\hline \multirow[t]{2}{*}{ Southern } & Greater-Accra & 5 & $\begin{array}{l}\text { Male } \\
\text { Female }\end{array}$ & $\begin{array}{l}6 \\
4\end{array}$ & $\begin{array}{l}\text { Male } \\
\text { Female }\end{array}$ & $\begin{array}{l}4 \\
4\end{array}$ \\
\hline & Volta & 5 & $\begin{array}{l}\text { Male } \\
\text { Female }\end{array}$ & $\begin{array}{l}5 \\
5\end{array}$ & $\begin{array}{l}\text { Male } \\
\text { Female }\end{array}$ & $\begin{array}{l}5 \\
3\end{array}$ \\
\hline \multirow[t]{2}{*}{ Middle-Belt } & Ashanti & 6 & $\begin{array}{l}\text { Male } \\
\text { Female }\end{array}$ & $\begin{array}{l}6 \\
9\end{array}$ & $\begin{array}{l}\text { Male } \\
\text { Female }\end{array}$ & $\begin{array}{l}6 \\
6\end{array}$ \\
\hline & Bono-East & 6 & $\begin{array}{l}\text { Male } \\
\text { Female }\end{array}$ & $\begin{array}{l}6 \\
7\end{array}$ & $\begin{array}{l}\text { Male } \\
\text { Female }\end{array}$ & $\begin{array}{l}6 \\
8\end{array}$ \\
\hline \multirow[t]{2}{*}{ Northern } & Upper West & 6 & $\begin{array}{l}\text { Male } \\
\text { Female }\end{array}$ & $\begin{array}{l}4 \\
7\end{array}$ & $\begin{array}{l}\text { Male } \\
\text { Female }\end{array}$ & $\begin{array}{l}4 \\
2\end{array}$ \\
\hline & Northern & 6 & $\begin{array}{l}\text { Male } \\
\text { Female }\end{array}$ & $\begin{array}{l}6 \\
5\end{array}$ & $\begin{array}{l}\text { Male } \\
\text { Female }\end{array}$ & $\begin{array}{l}8 \\
2\end{array}$ \\
\hline Total & & 34 & & 70 & & 58 \\
\hline
\end{tabular}

Source: Authors

The selection of key informants began at the national level, with a desk review to identify departments and stakeholders involved in the PFJ program (MoFA 2017). Four nationallevel stakeholders were interviewed, specifically Ministry of Food and Agriculture (MoFA) representatives from the Policy, Planning, Monitoring, and Evaluation Directorate; the Planting for Food and Jobs Secretariat; the Plant Protection and Regulatory Services Directorate; and the Directorate of Crop Services.

National-level interviewees also provided guidance on who to interview in each study district: the District or Municipal Director of MoFA; the PFJ Desk Officer, if present in the district; the PPRSD Officer, if present; Agriculture Extension Agents (AEA); input dealers; and the Nation Builder's Corps (NABCO) officer. When possible, interviewees were selected who had participated in the PFJ input distribution in the 2019 production season.

Enumerators obtained the support and authorization of the district MoFA offices to conduct the study. In the arrangement of local key informant interviews, local MoFA officers introduced the study and the study team members. Input dealers were selected with the help of the AEAs, who identified the most patronized input shops in their districts

Farmer communities were stratified by district and selected randomly from the survey sample of a related study that had been done by the Institute of Statistical, Social, and Economic Research. Farmers were purposively sampled to represent a diverse set of criteria in line with a maximum variation sampling approach. The sample of farmers was designed to capture important differences in experiences (Marshall 1996), beneficiary status, gender and female headship, wealth and land ownership, and age.

\section{Analysis}

Interviews were recorded, with permission from the interviewees, and then transcribed. Any interviews not recorded were captured with detailed field notes. Records of the key informant interviews also included photos of the pen and paper process-net maps. Microsoft Excel was used to organize data from the process net-map analysis, yielding an aggregated process description for national and district levels. Transcribed interviews were analyzed in NVivo 15 
(QSR International), to identify patterns of responses across interviews, to highlight important similarities and variations, and to identify illustrative quotations.

\section{Limitations}

The study has some limitations that should be considered when applying the lessons and suggestions drawn from it. First, while attention was paid to the sampling of districts such that the selected districts represent key differences throughout Ghana, the experiences in these six districts may not capture experiences throughout the country. There were significant differences in implementation processes and procedures across these six districts. It would be safe to assume that analysis of other districts would find additional differences. However, in spite of these differences, the extent to which our analysis found similar challenges and benefits across the six districts suggests that this study can provide important insights that are likely to be largely consistent throughout Ghana.

Second, this study does not try to assess the totality of the PFJ program or even the PFJ input subsidy program. Because of major differences in the procurement and distribution processes of the seed subsidy component compared to the fertilizer subsidy component, it was necessary to choose one. In this study we choose to analyze the fertilizer process. However, we strongly suggest a follow-up study be done to assess the seed distribution process.

Last, we focus our analysis on the 2019 growing season and prompted respondents to limit discussions to their experiences during that year. However, some recall error is possible - in some cases respondents seems to describe processes from previous years - and delays in data collection due to COVID-19 may have exacerbated this problem. To mitigate this, statements that were clearly related to previous years or for which respondents were unsure of the year to which they were referring were not considered in this analysis.

\section{NATIONAL-LEVEL PROCESS MAP}

In this section we summarize the prescribed PFJ fertilizer distribution implementation process as described by national level key informants. This section provides a broad understanding of the actors that were intended to be involved and the expected steps that would be followed in the process of distributing subsidized fertilizer.

At the national, regional, and district levels, the main stakeholders in the implementation of the PFJ program are government officials and employees, primarily from the Ministry of Food and Agriculture (MoFA). Figure 1 lists the key directorates and personnel from MoFA with explicit roles in PFJ implementation, as described by key informants. Given the vast mandates and responsibilities of the any MoFA directorate, for the purposes of this report we describe only those directorates with roles directly relevant to PFJ fertilizer distribution. 
Figure 1. Key directorates of the Ministry of Food and Agriculture involved in the Planting for Food and Jobs Program

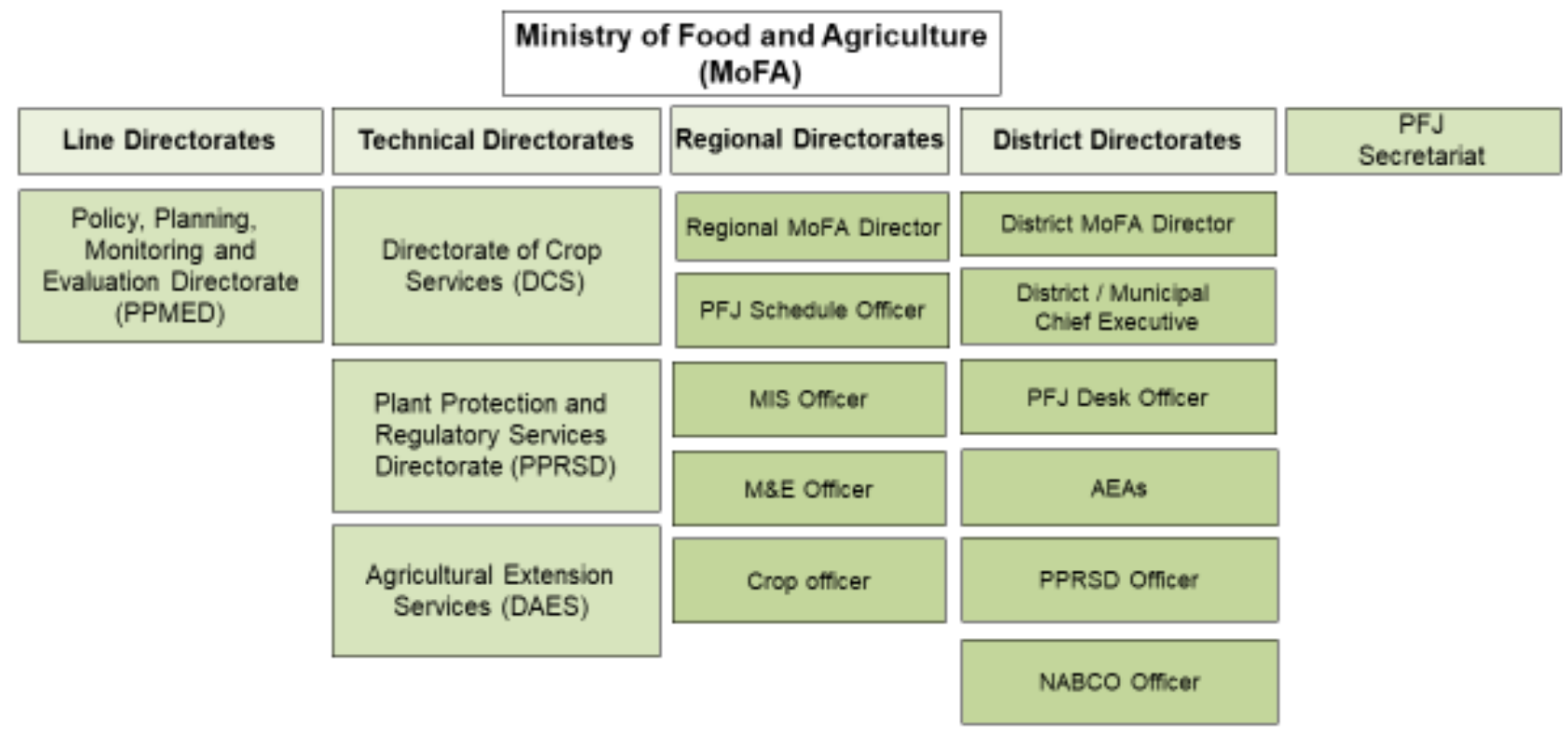

Source: Authors' presentation of data from MoFA

Note: $\mathrm{AEA}=$ Agriculture Extension Agent; M\&E = Monitoring and Evaluation; MIS = Management and Information Systems; $\mathrm{NABCO}=$ Nation Builder's Corps; PFJ = Planting for Food and Jobs program.

- The Policy, Planning, Monitoring and Evaluation Directorate (PPMED) manages the budgeting and overall monitoring and evaluation (M\&E) processes within MoFA, and as such is closely involved in the planning, budget preparation, and M\&E of PFJ.

- The Directorate of Crop Services (DCS) is responsible for awarding procurement contracts or directly procuring inputs (fertilizers and seeds), as well as monitoring, data collection, and reporting on PFJ activities jointly with the PFJ Secretariat. DCS receives daily and monthly sales information from the regions and matches that data with sales collated from input suppliers' invoices.

- The Plant Protection and Regulatory Services Directorate (PPRSD) monitors seed and fertilizer quality, as well as pest management issues as they relate to PFJ, e.g., pesticides were supplied as part of PFJ in the fight against fall army worm. PPRSD also maintains a register of input dealers and keeps records of the quantities of inputs that companies can supply. PPRSD conducts quality assurance tests of inputs before they are supplied to farmers.

- The Directorate of Agricultural Extension Services is responsible for overseeing extension service delivery in the country. As such, it handles the agricultural extension aspects of the PFJ program as a part of its mandate to provide technical advisory services and information on agricultural technologies to all who need it.

- Although the PFJ Secretariat is a special unit outside of MoFA's organizational structure, it works alongside PPMED and DCS to monitor and coordinate PFJ activities, collect and compile data on program implementation, and periodically reports on PFJ activities, input supplies, and the deemed impacts of the program directly to the Minister of Agriculture. 
Within the Regional Directorates of MoFA, PFJ Schedule Officers, M\&E Officers, and Management Information Systems Officers help compile data on the program that is received from districts and prepare a report for the Regional MoFA Director. Crop Officers oversee all crop-related PFJ activities, e.g., setting up crop demonstration plots. The roles of the Crop Officers overlap to some extent with those of the Agricultural Extension Agents (AEA), who work at the district level. However, Crop Officers do not conduct farm and home visits as the AEAs do.

At both the national and district level, the private sector plays a crucial role in PFJ implementation. The private sector is responsible for some input production, especially of seed, as well as importing, packaging, and distributing the subsidized seeds and fertilizers that are the bedrock of the PFJ input program. The private sector has also been involved in efforts to implement a biometric farmer database system.

In the context of this report, the term "input suppliers" is used to refer to those private sector firms that are responsible for importing or the local blending of fertilizer products, as well as for wholesale trade in inputs. In contrast, "input dealers" refer to retailers or shop owners who sell farm inputs directly to individual farmers at the district or community level. Inputs suppliers typically own or form part of the retail networks in districts through which agricultural inputs are distributed.

Interviews with national-level stakeholders yielded important insights about the complex process involved in the implementation of PFJ. Stakeholders also highlighted challenges faced at specific steps of the implementation process. Most of the steps in the implementation of the PFJ input subsidy program at national level are largely administrative and unseen by the beneficiaries. However, whether these steps are implemented properly has a considerable impact on the timeliness of the program for farmers. Moreover, the national PFJ input subsidy program process provides an outline of the intended process of program implementation at the local district level.

\section{Step 1: Planning and target-setting}

At the national level, the PFJ fertilizer distribution process begins with a management meeting by the Minister of Agriculture, DCS, and the PFJ Secretariat. At this meeting, the subsidized input distribution of the previous growing season is reviewed and plans for the coming season are made. National-level targets for quantities to be distributed and number of beneficiaries are determined at this time. This meeting is typically held in August or September before the growing season.

\section{Step 2: Registration of input suppliers and retailers}

Input suppliers and retailers must register each year with the PPRSD. Registration certificates must be obtained each year to enable a firm to participate in the PFJ program as a supplier or retailer. Registration is done on paper at PPRSD district and regional offices. Registration forms are sent to the PPRSD head office in Accra. When approved, signed certificates from Accra are returned to dealers. Suppliers and retailers can register at any time of the year.

\section{Step 3: Advertisement, announcement of tenders, and submission of bids}

DCS and the procurement unit advertises tenders for agricultural inputs through the media. There is a six-week period during which input suppliers must send in their bids and 
technical documents to the procurement office. Suppliers applying for a tender must be registered with PPRSD when this process starts in September.

\section{Step 4: Evaluation of bids and selection of suppliers}

In November each year a five to seven-member evaluation committee set up by the Minister of Agriculture and chaired by the DCS Director assesses the bids and other documentation submitted by input suppliers. The committee includes representatives from the Procurement Unit, DCS, PPRSD, and the PFJ Secretariat. The committee selects suppliers within two weeks of the submission deadline. Selection is based on suppliers' capacity to distribute inputs throughout the country.

\section{Step 5: Notification of suppliers and awarding of contract}

The selected suppliers are notified and issued offer letters, including quantities and designated regions where they may distribute inputs. Suppliers have ten days to accept or reject offers made by the committee. Contracts are awarded to suppliers by the Minister and drawn up by the Procurement Unit. All contracts are awarded by 31 December to ensure suppliers have enough time to procure and import inputs in time for the coming cropping season.

\section{Step 6: Application for import permit and tax waiver}

Input suppliers must then apply for an import permit and tax waiver from MoFA. PPRSD advises as to which input suppliers are registered and in good standing and, thus, can be granted the permit and tax waiver. This process takes about two weeks to be completed.

\section{Step 7: Import and inspection}

When imported inputs reach the port, PPRSD officers inspect the consignments to check quantities and types of inputs. Samples of inputs undergo quality testing, which is carried out by PPRSD, before the inputs are approved for distribution.

\section{Step 8: Distribution}

Suppliers then send the inputs to their distribution networks or retail outlets in the districts allocated to them in their contract with MoFA. When inputs reach the districts, suppliers notify NABCO officers, AEAs, regional Ministers, and district MoFA directors. The District Chief Executive (DCE) or Municipal Chief Executive (MCE) endorses the suppliers' waybills. Ideally, this process is completed by February.

\section{Step 9: Retailing of inputs}

PFJ fertilizer is sold at a subsidized price in retail shops, usually in the district center or local municipality. The MoFA officers in the regional and district offices ensure that all districts receive subsidized inputs. A NABCO officer is present in each retail shop to monitor sales and to record daily the quantities sold to farmers. Starting in the 2019 growing season, NABCO officers were given devices to record farmer details in order to create a biometric database.

\section{Step 10: Monitoring and reporting}

NABCO officers submit monthly sales reports to the regional MOFA office, which compiles a regional report to submit to DCS. Sales should continue through the major and minor seasons from March through October. Suppliers submit invoices and other documentation of inputs sold to DCS throughout the year. 


\section{Step 11: Payments of suppliers}

The administrative process for requesting and providing payments begins with DCS validating invoices submitted by suppliers by matching them with reports on subsidized input sales submitted by MoFA at the regional level. After the invoices are validated, DCS sends a request for payment of suppliers to the Minister of Agriculture to approve.

In addition to the steps described above, PPMED carries out M\&E activities for PFJ with funding from the Modernizing Agriculture in Ghana project of the Canadian government. PPRSD officers at district-level also conduct routine visits to retail shops to inspect the physical quality of inputs and to check the weight of inputs. The M\&E officers visit districts in two or three regions to speak with farmers and with regional and district agricultural officers. Among the information collected is impressions on the timeliness and quality of the PFJ inputs. After the monitoring visits are conducted, feedback is given to the Minister of Agriculture and some MoFA directors. The PFJ Secretariat submits quarterly reports of PFJ activities to the Minister. The Minister also conducts monitoring visits to all the regions and speaks with stakeholders assess how the program is being implemented.

National level informants noted a few important challenges related to this process. The late arrival of fertilizer was a common complaint. Several respondents identified the complex and time-consuming tendering and registration process for suppliers described above as a major contributing factor to the late arrival of inputs. One respondent suggested that starting the process earlier in the year would improve the timeliness of fertilizer supply. Another noted that the paper-based registration system could be made electronic to increase efficiency. However, it was noted that major delays in input delivery experienced in 2018 were improved in 2019.

Monitoring of the quality of inputs was also mentioned as an important area for improvement by multiple respondents. It was noted that problems with the previously employed coupon system - especially counterfeit coupons - were addressed by abandoning the use of coupons. Related issues related to farmers receiving more than their share of subsidized inputs were said to be increasingly addressed by the development of an accurate farmer database, a process being led by NABCO officers.

\section{DISTRICT-LEVEL PROCESS MAP}

In this section we present a detailed discussion of PFJ subsidized fertilizer distribution at district-level and the role of the stakeholders involved. The process steps were defined using information collected from key informants and from beneficiary and non-beneficiary farmers across the six study districts. Differences across the study districts are highlighted where relevant.

Within the districts, the following MoFA roles are the most important for the implementation of PFJ:

- District Directors (DD) supervise the implementation of the PFJ program on the ground and report to the Regional Directorate. Reporting is aggregated at regional level for reporting at national level.

- District and Municipal Chief Executives (DCE/MCE) are involved in the monitoring processes, largely in endorsing waybills. These are the shipment documents 
provided by an input supplier or distributor. The interviews did not obtain details on the waybills used. DCEs are also involved in some sensitization of farmers and program officials, in information sharing components of PFJ, and in the input request process carried out by input dealers.

- PFJ Desk Officers (PFJDO) play various roles, all related to assisting with notification about PFJ program parameters and sensitization of farmers. PFJDOs also help monitor the delivery of inputs to input dealers by checking waybills or sending NABCO officers to do so. PFJDOs also help monitor the sale of inputs, checking the reconciled daily record sheets obtained by NABCO officers from input dealers to ensure that the farmers listed are true beneficiaries. This is done by contacting the farmers via the phone numbers listed on the daily record sheets.

- Agricultural Extension Agents (AEA) sensitize communities and farmers about the PFJ program and register beneficiaries. AEAs also provide extension advice to farmers.

- Nation Builders Corps Officers (NABCO) are assigned to the PFJ program from NABCO, a youth employment program that employs people across the Ghanaian government. Those assigned to MoFA work essentially as junior AEAs and have a specific watchdog role in the context of PFJ implementation.

- Plant Protection and Regulatory Services Directorate (PPRSD) staff assigned to districts conduct routine visits to the inputs shops to inspect the physical quality of the fertilizers and seeds as well as their weight. They also conduct some extension activities regarding pest control.

Unlike at the national and regional levels, at the district level direct beneficiaries, communities, and non-governmental organizations interact with the government officials and private sector involved with implementing the PFJ fertilizer subsidy program. Aside from the farmers who benefit, the communities in which they live are also important for the PFJ program. Much of the sensitization and information sharing around PFJ is done at the community level through word-of-mouth, rather than through outreach to specific farmers. Additionally, farmer-based organizations are involved in PFJ as the groups are used to distribute inputs among members. NGOs play a more minor role in the 2019 PFJ implementation, mostly through sensitization efforts and implementation of complementary programs. NGO assistance with sensitization was mentioned by key informants in the Northern Region specifically.

District-level interviews converged on a set of 17 steps in implementing the PFJ fertilizer subsidy program in 2019. These steps are described here and are shown graphically in Figure 2.

\section{Step 1: Officials informed about program parameters}

The first step in the PFJ fertilizer subsidy program implementation process begins after targets are determined and tenders have been issued to suppliers at the national level (national Step 6). District-level officials are informed by their superiors at national and regional levels about the program parameters for the season. Given that these parameters, e.g., input quantities available, types of subsidized inputs, and costs to farmers, typically change from year to year, this is an important task. 
Figure 2. Process Net-Map of district-level Planting for Food and Jobs Program activities and actors

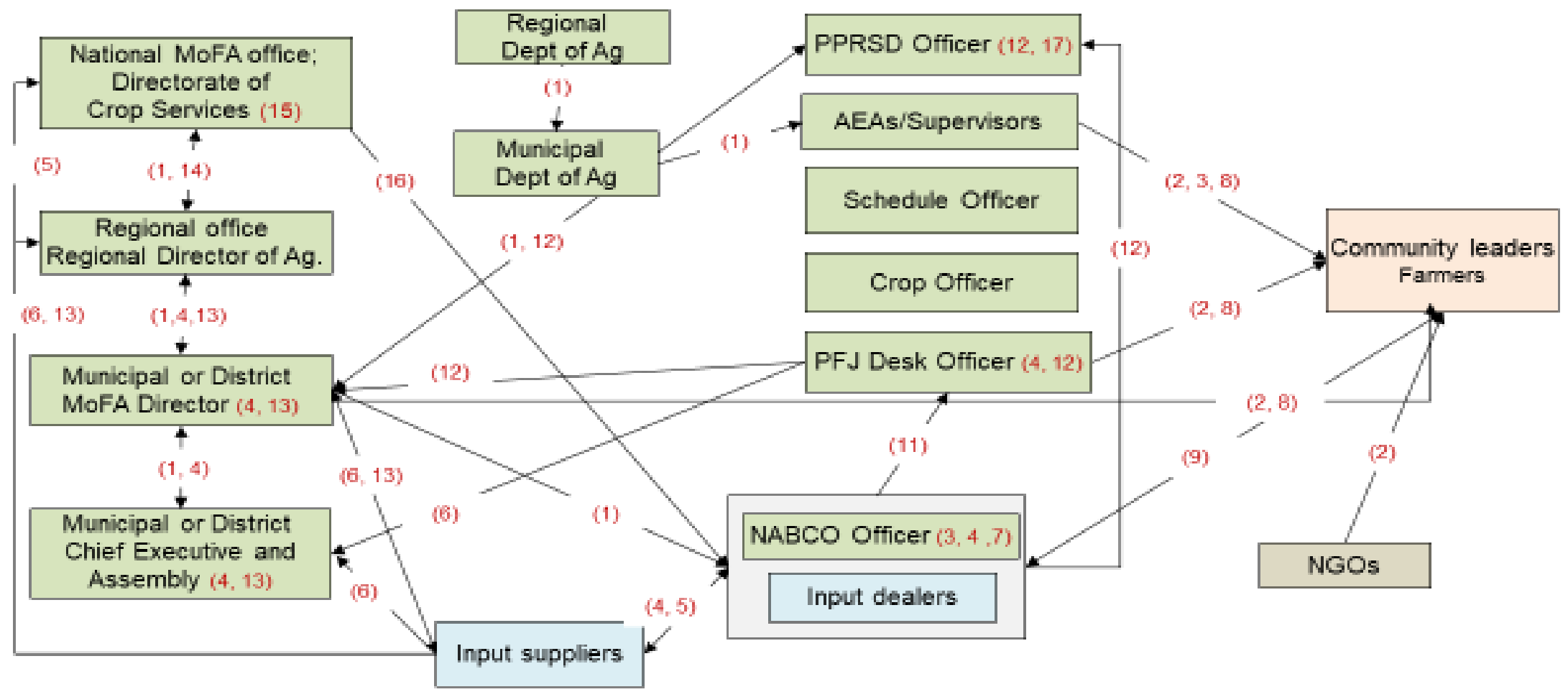

1. Ofricials informed about program parameters (letters, emails, WhatsApp, radio) 10. NABCO officer and input dealer keep daily record sheets

2. Sensitization of farmers/communities (radio, meetings, notice boards, calls) 11. Signed and reconciled daily record sheets submitted - monthly
3. Farmers registered; listing updated
12. Check daily records sheets, endorse, fill Form $A-$ monthly

4. Request inputs (call, official letters)

13. Endorse and submit Form $A$ - monthly

5. Inputs delivered to the input dealers

6. Notification that the inputs (fertilizer) have been delivered

7. Check the incoming input consignment against waybill

15. Form C prepared - monthly

16. Payment made - monthly

8. Notify farmers that inputs are available for purchase (radio, meetingsidurbar) $\quad 17$. Monitoring of registration, input availability, banned chemicals

9. Distribution; farmers go to the input shop with ID to purchase

Source: Authors presentation of data

Note: AEA = Agriculture Extension Agent; MoFA = Ministry of Food and Agriculture; NABCO = Nation Builder's Corps; PFJ = Planting for Food and Jobs program; PPRSD = Plant Protection and Regulatory Services Directorate. 
District respondents reported that they started receiving information on the 2019 program parameters between January and February. They reported being notified through various modalities, including official letters, emails, radio announcements, WhatsApp messages, or through PFJ-focused meetings.

\section{Step 2: Sensitization of farmers}

The next step entails sensitizing farmers and communities regarding the design of the PFJ program in a given year, developing or updating a list of farmers who want to participate and obtaining information on the amount of cropland they have, and finally formally registering the farmers. The way in which these activities were undertaken varied greatly across the districts studied.

Farmers were most frequently informed about the program through the radio, television, and AEAs. Other modalities mentioned by district officials, but not by farmers, included newspaper announcements, an "information van", posters on public notice boards, and meetings of community leaders. AEAs shared information in communities either in group meetings or individually. Sensitization also was done by interacting directly with farmer-based organizations or through larger community meetings. All respondents, including non-beneficiaries, had heard of PFJ in their localities.

Input dealers also had a strong incentive to help sensitize and provide information to farmers, as they view it as an opportunity to increase their customer base and expand sales:

.... whenever I will be invited, I also make sure that I will be able to identify farmers who will also patronize my products. And [if] ... I can identify some leaders, especially farmer group leaders, and liaise with them, they do the job on my behalf. Whenever they need a product, through their leadership, they are able to get them (Input dealer, Bono-East Region).

\section{Step 3: Registration and listing of beneficiaries}

The listing process was described as the updating of the previous year's beneficiary list, detailing which farmers were interested in receiving subsidized inputs and the amount and type they required based on land size and crops produced. Registration was described as the formal collection of beneficiary information, a process that requires farmers to show their identity documents. There were major differences between districts in the way these steps were implemented and a lack of clarity about the purposes of the steps. In some districts, listing was described as the mechanism for estimating the quantities required. In other districts, the listing was not done, and registration took place before the inputs arrived in the district. In other districts, farmers were told to simply bring their IDs to the input shops and register at the point of purchase.

Based on our national-level interviews, it is clear that monitoring of sales is a requirement and that biometric machines were meant to be employed during registration to yield a more comprehensive database of farmer beneficiaries and to ensure farmers could not purchase more than their allotment. The extent to which MoFA district officials are involved in estimating quantities required and making requests for inputs, versus input dealers doing this, seems to vary by location.

Multiple respondents reported that listings were updated periodically but updating was not done explicitly in 2019. Others reported it did not happen at all. When asked about whether any beneficiary listing was done in 2019, a DD in Greater Accra replied, "No, for 2019, the directive is for the farmers to just go to the shops and buy their inputs" (District Director, Greater Accra Region).

AEAs were most commonly cited as responsible for registering farmers, although NABCO officers, PPRSD officers, and PFJ Desk Officers were also said to be involved in some areas. Most 
key informants mentioned that tablets or similar devices were provided to NABCO officers for biometric registration. However, it was commonly reported that the devices were either not useful due to connectivity limitations or the officers were expressly told to stop using them at some point during the 2019 season. A NABCO officer in Northern Region noted some problems with the system: "At some point in time during the sales of fertilizer, you will finish registering the farmer and when you want to verify, the machine will not allow you to do so." Similarly, a NABCO officer in the Ashanti Region explain that they stopped using the new system: "... even the biometric, we didn't use it the whole year. It got to a point it was even worse. So, they have to move it out and then we use only the ID cards."

Farmers noted that the process of registration started and often coincided with sensitization. "We pass it through the agricultural extension officers; they will come to tell us all about the program. When the time is due, they will come and meet us, writing down our names and the amount we each want to purchase and send it." (Beneficiary male, Northern Region). In three of the six districts difficulties in registering were mentioned, primarily due to long queues during the registration process: "Yes, I did face some challenges with regards to the registration as it involves queuing, and some of the community members were playing politics with it." (Beneficiary male, Upper West Region)

In five of the six districts it was noted that it is easier to register and receive inputs if you were involved in a group or cooperative: "If you involve yourself with those who are already taking it, your name will be added that way. When it comes, you can also go and buy." (Beneficiary male, Northern Region)

It is also unclear whether the registration processes and listings were used to distinguish between who could and who could not purchase inputs from the shops once inputs became available. Some farmers were required to register ahead of time and others were not. In other words, registration was inconsistently applied as a prerequisite for receipt of inputs later in the implementation process.

\section{Step 4: Requesting inputs}

The role of the district in determining the allocation of fertilizer varied across study districts. Some respondents suggested that the district MoFA office was tasked with estimating and requesting input quantities needed - described as quotas by officials. In Ashanti Region, a PFJ Desk Officer reported that he and the district MoFA Director use hard copy forms to detail the quantity of certain inputs they needed. They submitted these forms to the Regional Office. In Bono East, an AEA explained that the reports from AEAs in operational areas were collated by the DD, who generated a paper-based report to request inputs.

At the district level we will write and tell the regional that for this year maybe NPK we will need this quantity, seed we need either rice seed, maize seed and all those involved. But at the end of the day the suppliers will go directly to the input dealers who have been registered ... So, the input dealers will now also make their own request to their suppliers or distributors. We will give a projection of the quantity we need for the year and that will be part of the national planning for the country. Specifically, for our district, this is the quantity they may try to supply to our farmers. At the request point, it is usually the distributors that are assigned to supply to various districts. So, the distributor in charge of this particular district will make his own request based on the retailers' requests given to them. The request is in a chain, and it goes through the private sector. We will only go there to monitor, but the purchasing and all those we are not involved. We only monitor the movement and distribution chain of those products (PFJDO, Northern Region). 
...with that registration, we pushed it to the regional [office] and they also forwarded it to national...So, per that one, they have a quota... (PPRSD, Upper West).

However, by some accounts, input suppliers received their quotas from the national level, and input dealers order them from the input suppliers using a waybill. Often, the input dealers directly requested inputs through phone calls directly to the suppliers, generally between March and May.

Now we don't request. Rather, they give us quotas from the national level. Maybe, 'Upper West this is your quota for seeds and fertilizers' and also gives us the names of the companies (Director, Upper West).

They [dealers] know their capacity [in terms of money and demand], so they just request any quantity they feel they can sell (PPRSD Officer, Ashanti).

National-level interviewees noted that the overall targets are set based on numbers from the previous season, while they also note that the district level officials are responsible for ensuring sufficient supplies of fertilizer in their areas.

\section{Steps 5 to 7: Input delivery to shops}

Input suppliers deliver the products directly to the input dealers (Figure 2, Step 5). This triggers a notification to the district-level MoFA officers involved with the PFJ subsidized fertilizer distribution that the inputs have been delivered. This then results in someone coming to monitor the offloading of the delivered inputs. Who fills these roles seems to depend on the district, but PFJ Desk Officers and NABCO officers seem to be charged with the direct monitoring of the delivery and checking the consignment against the waybill (Figure 2, Step 7).

So, if the product comes, we make sure that it's subsidized fertilizer with label printed "Planting for Food and Jobs" on the fertilizer before. Then we also check the waybill; the number that was ordered for, is it the same on the waybill? Before we accept for the things to be offloaded in our shops before selling. That's how we monitor. (NABCO officer, Bono-East Region).

Upon delivery of inputs to the dealers, input suppliers must submit their invoices to the Directorate of Crop Services. Across different districts, input dealers submit waybills to different officials, although the reason for this variation is unclear.

\section{Steps 8 and 9: Input distribution}

Farmers purchased subsidized fertilizer directly from input dealers under the observation of a NABCO officer to oversee the distribution and to collect farmer information. The input provision process was described as straightforward for farmers, who only had to show up at the input shop with an identification card and money with which to purchase the subsidized inputs. However, as discussed above, some farmers said they were required to register beforehand with AEAs, while others said they could register at the point of purchase. Most mentioned needing a national voter ID card or a National Health Insurance Scheme card to register or to access inputs. Key informants often stated that a voter ID was the standard requirement for collecting inputs, although some said that ultimately inputs would be sold to people even without IDs.

One has to register with the AEA officer with your ID before you can benefit (Nonbeneficiary male, Upper West Region)

You are to go with your ID card, but we saw that some people came without a card too. Later on, the directives came that if the person doesn't have an ID card, you can still sell it to him or her (Director, Bono-East Region). 
Notification of when inputs are ready for purchase seems to happen in an ad hoc manner. Multiple district-level key informants reported that farmers just visit the shops to find out whether the inputs had arrived, rather than being explicitly notified. Sometimes input dealers and NABCO officers were reported to just have told the beneficiaries about the subsidized inputs when they were in the input shop.

Sometimes the farmers come to the shop and ask when the fertilizers are coming in and we also tell them that yeah, this period it will come; based on the information we have from above. And also, because the farmers have done the work continuously, they have experience, some of them also know when the farming season starts. So, if they come to buy other farming, they ask "when are the PFJ inputs coming?" so we tell them, oh, this month it is coming, this week it is coming. So immediately the things are in, they also come in for them (NABCO officer, Bono-East Region).

This may mean that farmers in need of subsidized inputs have to spend time and possibly money to travel to shops without the certainty that they will receive subsidized inputs on a given day. However, there is an impression amongst some officials that word-of-mouth notification is sufficient, while other lament not being sufficiently well-informed on the timing of the delivery of subsidized inputs to input retailers in order to notify farmers:

[Farmers] were notified by the retailers themselves and also from their colleague beneficiary farmers. Maybe someone who had come there to purchase will send the information to the other beneficiaries about the availability of inputs in that particular retail shop. ... because if one farmer registered and had the inputs to buy at the retail shop, definitely the information will get to the other farmers (NABCO officer, Northern Region).

...I had the information regarding the availability of inputs later. When it came, I was not informed about it. But later about a week to that I was asked by Director to join the District Assembly stores who was in charge of it. Because we are under local government, they normally pass it through Assembly (AEA, Northern Region).

\section{Steps 10 to 17: Monitoring and reporting}

In addition to monitoring the delivery of subsidized inputs to the input dealers' shops, other monitoring activities include the keeping of daily record sheets that track individual sales of subsidized inputs by input dealers. These daily record sheets are kept separately by input dealers and NABCO officers. The records sheets are then collated, and the information compiled onto several forms (Forms A, B, and C), which are submitted at various levels of government as part of the monitoring of the amount of subsidized fertilizer for which the government pays suppliers. The forms are generally completed monthly once input sales begin, although in some places the forms were submitted quarterly. There was wide variation in the number and types of district-level officials involved in this process.

Most monitoring and reporting processes were reported to have been done using paper-based forms sent in hard copy. However, some officials reported the use of desktop computers or laptops as well. Some soft-copy documents are also sent electronically:

The primary paper forms being used are:

Daily record sheets are kept simultaneously by inputs dealers and NABCO officers and later reconciled. These forms track, at a minimum:

- Beneficiary name (supposed to be verified with ID)

- Beneficiary contact (mobile phone number)

- Date input was purchased 
- Quantity of input purchased

- Type of input purchased

However, some record keepers recorded additional information (e.g. farm size), such that there was not a standardized process for what information was needed.

Details like the name of the farmer, you inspect the voters ID card, whether the person is a Ghanaian and the community he is coming from, his farm size and all that information using our own template (PPRSD officer, Bono-East Region).

In the process of checking the daily records sheets, officials (PPRSD officers or PFJ Desk officers) may call individual farmers to confirm that the farmers listed are real individuals.

For cross checking, when [daily records sheets] get here too, you call the phone numbers to confirm, randomly call some of the numbers before the form-A is prepared (PPRSD officer, Upper West Region).

Sometimes, I even call some farmers on the list and ask them, did you buy fertilizer, and they say yes. I ask what quantity. At times I have challenges, what the people will put there will not be exactly what the farmer has bought (PFJDO, Greater-Accra Region).

Form A: Prepared with information about sales from individual input dealers reconciled from the joint recordkeeping of input dealers and NABCO officers. These forms are largely compiled by the PFJDO, although occasionally the PPRSD (Figure 2, Step 12).

The form is then passed to the District MoFA Director for endorsement and is sent back to the input suppliers (Step 13). This is done on a monthly basis. In some cases, Form A may be submitted directly from the District Directorate to the Regional Directorate for preparation of Form B.

Based on that, you prepare the Form A for the input dealer to send it to the distributor for their payment (Director, Bono-East Region).

It appears that someone from the District Assembly, usually the District Chief Executive or Municipal Chief Executive, may also be responsible for signing off on, or endorsing, Form $A$ and the waybills.

Form $B$ is a regional-level version of Form A, compiling endorsed sales information on a monthly basis. This is endorsed by the regional Minister and the regional Director of Agriculture before Form $\mathrm{C}$ can be prepared at the national level.

[Form A] goes back to the regional, which is submitted there through the retailer to take Form $B$. Then the Form $B$ will also be endorsed and handed over to the distributor to take it to Accra (PFJDO, Northern Region).

Form C: This is the national-level version of Forms $A$ and $B$, compiling endorsed sales information on a monthly basis. It seems that the input supplier also brings this form to the national level for endorsement and payment. Form $\mathrm{C}$ must be signed before payments are made to the input suppliers.

This form ' $B$ ' will be carried to Accra at the national office, then a Form ' $C$ ' is prepared, and payment is made (PFJDO, Upper West Region).

Finally, there is monitoring of registration status of input dealers, input availability, and banned chemicals by the PPRSD officers. They also inspect fertilizers and pesticides and offer advice on these products. 
[PPRSD officers] went round to supervise or monitor the availability of inputs and also check the registration dates of the retailer whether they have duly registered or perhaps the registration has expired. And some of the chemicals have been banned from entering the country, so we also look out to see if those are available (PPRSD officer, Northern Region).

\section{FORMAL AND INFORMAL INCLUSION CRITERIA}

\section{General eligibility criteria}

Officials and input dealers involved in the provision of subsidized fertilizer are in general agreement about the formal criteria for inclusion in the program. However, some areas of ambiguity were raised, and in some districts informal practices favoring some farmers led to implicitly excluding other farmers.

While most officials and input dealers noted that the program is for small-scale farmers, some stated that the per person limit - the quantity of fertilizer sufficient for 5 acres - was available to any farmer. Either way, this per person limit was widely agreed upon.

Every farmer [is eligible] but mostly for subsistence farmers and subsistence farmers are those who have holdings of 5 acres or 2 hectares and below.... anybody above will have to go to a process before accessing it (Director, Volta Region).

So, it is open, everybody can access it, once you are doing farming within the municipality. Only that, as I indicated, commercial farmers are not allowed to benefit. Once you come and say, I have 100 acres, we are not supposed to. But if you are coming from a household and you are about five or ten people, everybody is entitled to five acres. So, in that wise, they come as individual farmers to pick as five acres (Director, Upper West Region).

There was also some suggestion of focusing on farmers who are able to pay for inputs, which implies targeting of better-off farmers:

We register farmers who can pay for the subsidized inputs when it is time. This is to get serious farmers on board for the PFJ program (NABCO officer, Upper West Region).

There was also some confusion about whether only Ghanaians could benefit. A NABCO officer from Bono-East Region reported that you must be a Ghanaian to benefit, but later reported that it would depend on whether you planned to sell your product in Ghana:

We demand for your ID card to verify whether you are a Ghanaian or not...depending on, if we ask you a question like do want to sell in Ghana here, fine. But if you want to sell outside, that means you won't get the direct beneficiary (NABCO officer, Bono-East Region).

While there was only one mention of eligibility based on target crops among respondents, the high rank of the government official who mentioned this criterion gives this point more weight:

Almost every farmer. Everyone who calls himself or herself a farmer. Unless the person is not cultivating the target crops, like in this our area, our target crops are maize, rice, soybeans, sorghum, and vegetables. If the farmer is not cultivating those types, he or she may be called ineligible. Let's say we cultivate yam and cassava in this area as well, which is not captured. So, if that is the only ones you are farming, it means that you will not benefit from the inputs. Some places, yes, but in Tolon District here it's not our target crops. Aside that, everyone is eligible (Director, Northern Region). 
When asked about eligibility for the program, beneficiary and non-beneficiary respondents indicated that the program is for all farmers. Others added that these farmers however must have farmland and have money to buy inputs. A few farmers, however, added that to be eligible, farmers must be in a group.

Previously, it was open to everyone, but when it reaches some stage, they started doing politics with it. When asked to explain, he responded "Yes, they will write names, you will form a group so you can go and collect the inputs." Aha! If you go solo, you will not be given. (Beneficiary male, Ashanti Region).

Farmers in the same household typically register separately and receive inputs individually. We also found that, whereas some farmers even from same households do not share inputs, others share inputs with other family members who did not register for program. This variation is expected given different gender norms across ethnic groups.

He registers as a different person; he buys his inputs when he has money, and I also buy mine when I have money (Beneficiary female, Northern Region)

A female beneficiary in a dual-headed household, when asked if she shared inputs with her spouse, responded,

No, he used all on his farm and I also used mine. In Ghana, we don't work together with the men because when they get the money, they won't give you (Beneficiary female, Ashanti Region).

When asked if he shared inputs with wife, another farmer responded:

Yes, she used my own. We farm on the same plot so when I buy it, we are all use it (Beneficiary male, Greater-Accra Region).

Me, my husband, and my rival (second wife of husband) use the input. Our husband does the buying and give us each ours to use for our various farms (Non-beneficiary female, Northern Region).

\section{Registration process}

As mentioned earlier, registration is no longer being done as a separate process in most places. Generally, listings from previous years are simply being updated.

But 2019 now that almost everybody is aware and almost everyone is participating, it doesn't actually compel us to register them because everyone keeps coming. They themselves will walk into the office and inform us they want this input... (Director, Northern Region).

[Registration and verification of beneficiaries who came to buy inputs] was just done simultaneously with the sales of the inputs which were from July to the end of the season ... (NABCO officer, Northern Region).

Yes, for this year after the sensitization, there was not much processing in enrolling (PPRSD Officer, Upper West Region).

... initially when they started, we did the registration using the laptops we have. Then later they came with some company, it seems ESOKO. So, 2017 we did our registration using the laptops, then ESOKO came with the biometric registration then ASNAK also did the same thing using the biometric registration for farmers. So, every year we just update those register and then we move on (PPRDSD officer, Bono-East Region). 
So, even after the registration, farmers still come around whether you have registered or not. Once you are within the catchment area, you will still get your inputs. But the registration of the farmers will give us some indication for projections (Director, Upper West Region).

Farmers indicated that it is difficult to participate in the program, referring specifically to the process of registration. Others did not participate in the program because they were unable to register in time, as indicated above. "I couldn't partake because the time I heard of it [referring to] registration was late so I couldn't register" (Non-beneficiary male, Upper West Region).

Another farmer added "I wasn't around as of the time they came to write down our names and so, before I got back, it was too late [to participate, although he benefited in previous season]" (Non-beneficiary male, Northern Region).

In general, while officials said that those who do not register can still receive inputs, there was mixed reporting on whether beneficiaries who did not bring IDs could purchase the inputs.

Some of the beneficiaries do not come with their IDs and expect the NABCO officer to sell the inputs to them (AEA, Upper West Region).

\section{Famer-based organizations}

In some regions, famer-based organizations accessed inputs and shared or distributed them to individual members. Some farmers indicated that AEAs encouraged that groups be formed or for farmers to join farmer groups to enable easy access to inputs. A few mentioned being denied inputs if they were not in a group. In Bono-East and Volta Regions, farmers were often encouraged by AEAs to form or join groups to benefit from the PFJ program.

If [farmers] join the group, they will get some [inputs]. [When asked if farmers could only benefit from PFJ by joining a group:] If they join, we have a sheet of paper that we write their names, so that when something happens, we know the number of people in the group. Aha! If we go there ... in the group, we have our representatives who receive it (inputs) on our behalf. They mention our group's name. At times, we meet with the Agric officers and they guide us to receive our inputs (Beneficiary male, Bono-East Region).

One female beneficiary said, "All we do is we go to the input dealers' shop as a farmer group in the community and that's when they will sell it to us." When asked if farmers would receive if they visited input shops individually, she reported that, "if it is the one the government has reduced for us when you go alone, they won't sell it to you. But with the one in the market, you can go alone and buy the amount you want" (Beneficiary female, Bono-East Region).

Similar experiences are reflected in the quotes below:

Yes, it is difficult for you as individual to get the inputs. Unless you join the group. (Beneficiary female, Bono-East Region).

Farming is available, but it's in groups. So, if you are not in it you can't possibly get involved. (Beneficiary female, Ashanti Region).

The person has to join a group of farmers who have been purchasing it from the past years before he can get his name to be added to the list of beneficiaries or the program. (Beneficiary female, Northern Region).

You must belong to the group. Yes, it is through the group that we can get it at a reduced price (Beneficiary female, Volta Region). 


\section{Remote communities}

Eight of the farmers interviewed reported that PFJ was not available in their communities: three in

Ashanti Region, two in Greater-Accra, and three in Upper West.

... Because my community happens not to be part of the lucky ones. (Non-beneficiary male, Upper West Region)

They say it [is] on the way, yet, I don't know [where] it ends up for me to go for some [inputs]. So, when the items come, it doesn't reach our community (Non-beneficiary male, Ashanti Region).

While we know that all small farmers are technically able to participate, it seems that some communities are left out, likely unintentionally. Accessibility of inputs to vulnerable and remote farmers was a concern mentioned by two of the national-level stakeholders interviewed.

And then the other problem is access to the community. At a certain period of the year, especially when it comes to rural application, most of the people come from communities where there is no access...Then, the other issue is, the early arrival of inputs. Farmers to be able to take advantage of it ...especially to the communities that are not accessible at the peak of the rain (Director, Upper West Region).

\section{CHALLENGES AND BENEFITS OF PARTICIPATION}

\section{Successes}

All district-level key informants were asked whether PFJ was meeting its objectives. The vast majority reported that it was, although not everyone agreed on what the objectives were. Most mentioned broad objectives of increasing crop yields and production, but only some mentioned the more granular objectives of the program, such as job provision, extension services, or food security.

As indicators of success, most key informants cited increased availability and affordability of inputs, specifically fertilizers. Additionally, informants mentioned increased food production or yields as evidence of the success of the program.

Others said the program was meeting its objectives, yet qualified the statement by highlighting outstanding issues to be addressed:

Yes, it is [meeting objectives] because all the corners you get the inputs to buy. The farmers are not being stressed in getting access to the inputs, so the only thing is being able to go through with the natural resources without failing, you will make it. We only have a fear of rainfall shortage but currently as we speak, we don't have any drought, yet the fields are looking good and they are performing (PFJDO, Northern Region).

\section{Input timing and shortages}

While the actual receipt of inputs was straightforward for most farmers, there were numerous reports by both key informants and farmers of input shops running out of subsidized inputs, leaving farmers with no option to benefit from the fertilizer subsidy component of the PFJ program. Farmers had to either leave input shops empty handed, or purchase inputs at full price. Shortages were reported in all regions in some form.

When the planting season is due, we sometimes do not get the right amount of inputs because of a shortage. We have been hearing from the local radio stations about the 
importance of applying the right amount of fertilizer on your farm (Beneficiary female, Northern Region).

However, it appears these shortages may be temporary:

There was shortage of fertilizer too for about a period of two weeks before it came back into the district (PPRSD officer, Northern Region).

Another challenged mentioned in five out of the six study districts is late arrival of inputs, which was also identified in the assessment done by Mabe, Danso-Abbeam and Ehiakpor (2018). Although a number of key informants noted that the timing has improved since 2018, farmers still complained about the timing: "Yes, it didn't come early and when you do that, we end up throwing it away" (Beneficiary female, Ashanti Region).

\section{Extension provision}

In all districts, beneficiary farmers reported improvements in yields. Respondents in five out of the six districts mentioned improvements in income or food security: "It has improved my income, and we are well secured when it comes to food" (Beneficiary male, Upper West Region).

Finally, some key informants and farmers highlighted the input provision combined with the extension information was a key benefit of the PFJ program.

...it has helped the farmers a lot and helped we the officers as well because we are very active and busy in sensitization and monitoring. This is because we know which particular inputs are coming and so it has made field visit effective. Is not just about distributing inputs, but monitoring the fields (Director, Northern Region).

The process from the Agriculture office is that when we get the fertilizer, we should prepare our land and plant them, and they will teach us how we would apply the fertilizer to get more farm produce (Beneficiary female, Bono-East Region).

Additional illustrative quotes from study respondents on key challenges to participating in the subsidized fertilizer component of PFJ are presented in Table 2, while Table 3 presents quotes from beneficiaries on the advantages they received through participation in the program.

\section{Table 2. Key challenges to participation in the Planting for Food and Jobs Program -}

illustrative quotes from both participants and non-participants

\section{Challenge}

or barrier to

participation

Cumbersome

nature of registration process

you

you have to wake up early and go to the place otherwise the place will be overcrowded. And the registration also takes time but apart from that there is no other problem. (Beneficiary female, Ashanti Region)

- At the point of writing down our names when this program was about to begin in our community here was really an issue of worry to us. Before you get your name on the list you have to suffer a lot before your name is written because the farmers were many.

(Beneficiary male, Northern Region)

Cumbersome $=$ I only had a challenge with regards to receiving the inputs as the cue was long and very process for stressful (Beneficiary male, Upper West Region) receiving inputs
- It was at the receiving that we had challenges as the cue was long and the men were stronger than us so when they come, there easily pick their inputs. (Beneficiary female, Upper West Region)

-... all though getting the inputs sometimes is tedious but when you are patient with the whole process you will benefit from it regardless. (Beneficiary female, Northern Region) 
Liquidity of cash to purchase inputs

- As for the inputs we know how to get them, the problem is the finances ... I don't have the money to purchase from another person. (Input dealer, Northern Region).

- Yes, they told us that they will bring the maize seed, but they gave it to the dealers and the price of the seed was high and because I was not having enough money, I didn't participate again. But I don't know for the other farmers if they did. (Non-beneficiary male, Ashanti region)

- I didn't have money as of the time farming activities had begun; I am a butcher as well, so my income was locked up with others too. (Non-beneficiary male, Northern Region)

- Enumerator: You said the reason you are not benefiting is... Respondent: Is financial reasons [in unison with enumerator] (Non-beneficiary male, Volta Region)

Patronage - One will wake up very early to form a cue and write the quantity of fertilizer you needed, and and misuse of inputs collect the fertilizer. If one complains, they speak anything to you. Those who even collect it don't farm, rather buy it to resell to farmers (Beneficiary male, Ashanti Region)

- Yes, I did face some challenges with regards to the registration as it involves cueing and some of the community members were playing politics with it. (Beneficiary male, Upper West Region)

-... Oooh, I did benefit from the other section of the village. You know the community is divided into three sections, so the other two sections are sections that always benefit from this program, Masa you everything is now politics as they have considered our section as $N D C$ [One of the political parties in the country]... (Beneficiary male, Upper West Region)

- The problem I encountered was, last year this place we farm for two seasons. After farming during the raining season and we entered into the dry season, when we went to buy the fertilizer we were told there is a shortage in the planting for food and jobs one [i.e., subsidized inputs] You can see that there's a PFJ sticker on the inputs, but you would be told it's finished and the ones available we have to buy it as outside price which got us worried. (Beneficiary male, Ashanti Region)

Shortage of -People were hauling the fertilizer so we couldn't get some to buy. The issue was widely inputs spread on radio and to the extent that some of the people involved were arrested. Enumerator: $\mathrm{Hmmm}$, so they were hauling the fertilizers and they told you it was finished when you could see it there? Respondent: Yes (Non-beneficiary male, Ashanti Region)

- At a point, we have some shortages. Anytime there is shortage in certain commodities, people will arbitrarily increase the price of these commodities. So, at a point, farmers where struggling trying to get fertilizer (Director, Upper West Region).

- It happens at times. In case there is a shortage, you will be asked to go to a different shop. (Beneficiary male, Volta Region)

- Yes, but the difficulty sometimes is you go to the shop with your money and the inputs will be finished so if they could make it available anytime so that when you need it to buy you get. (Beneficiary female, Northern Region)

- Well I have to say with that is sometimes the inputs will be in alright but the input dealer who is close by or supplies the community might not have it, so you have to Journey to Tamale to get it. So, if they could make it available to the input dealers on time it will save us the headache of travelling far to get it. (Beneficiary male, Northern Region)

Need to be in - Yes, you have to be part of the group before you can receive the benefit. (Beneficiary a group to female, Bono-East Region)

- If you involve yourself with those who are already taking it and your name will be added that way when it comes you can also go and buy. (Beneficiary female, Northern Region)

- The person has to join a group of farmers who have been purchasing it from the past years before he can get his name to be added to the list of beneficiaries or the program. (Beneficiary male, Northern Region)

- You must belong to the group before someone can benefit, we need to inform the Technical Officer to register the person before they can benefit. (Beneficiary male, Volta Region)
Mentioned in four out of six districts

Mentioned in five out of six districts 
- Yes, it didn't come early and when you do that, we end up throwing it away. And I always tell Men of inputs my sister, Akosua, if you had made us sow our old maize, it could have yielded results. If you use a tractor on one acre of land, it is $\mathrm{GH} \phi 100.00$ so five acres is $\mathrm{GH} \phi 500.00$ including the chemicals and manure used and all that. I have even lost count of the money spent in this maize cultivation which resulted futile (Beneficiary female, Ashanti Region)

- The time they [we] were given the fertilizer, it was late, so the maize couldn't mature well. (Beneficiary female, Bono East Region)

- Sometimes it doesn't come on time, fertilizer is supposed to be with we the farmers immediately [when] we start farming so that as and when its required for the farm you just apply it. We have been hearing of the education on radio every now and then. (Beneficiary female, Northern Region)

- Sometimes it [late arrival] affects us and it delays our harvest and our crops are left to rot on the farm (Beneficiary female, Volta Region)

Unavailability - The problem I encountered was, last year this place we farm for two seasons. After farming in minor during the raining season and we entered into the dry season, when we went to buy the

season fertilizer, we were told there is a shortage in the planting for food and jobs one (Subsidized inputs.) You can see that there's a PFJ sticker on the inputs, but you would be told it's finished and the ones available we have to buy it as outside price which got us worried. (Beneficiary male, Ashanti Region)

- I am happy you've brought this up, if you had not asked, I would even have said it, because anything of the government always comes late. We are now in the minor season and every farmer is preparing what they need to start cultivation and clearing of their land, so this is the time that the inputs must be available for us. So, if it is money, fertilizer, chemicals, it should be available by now or even an information should be shared with us that the inputs will be arriving soon or on this date, but you will cultivate your seed, and even sometimes go to town to buy the expensive fertilizer before the subsidized fertilizer will come. So, the time the inputs arrive is very late and does not help us the farmers. (Beneficiary female, Ashanti Region)

Source: Authors presentation of data

\section{Table 3. Key benefits to participating in the Planting for Food and Jobs Program - illustrative quotes from beneficiary farmers}

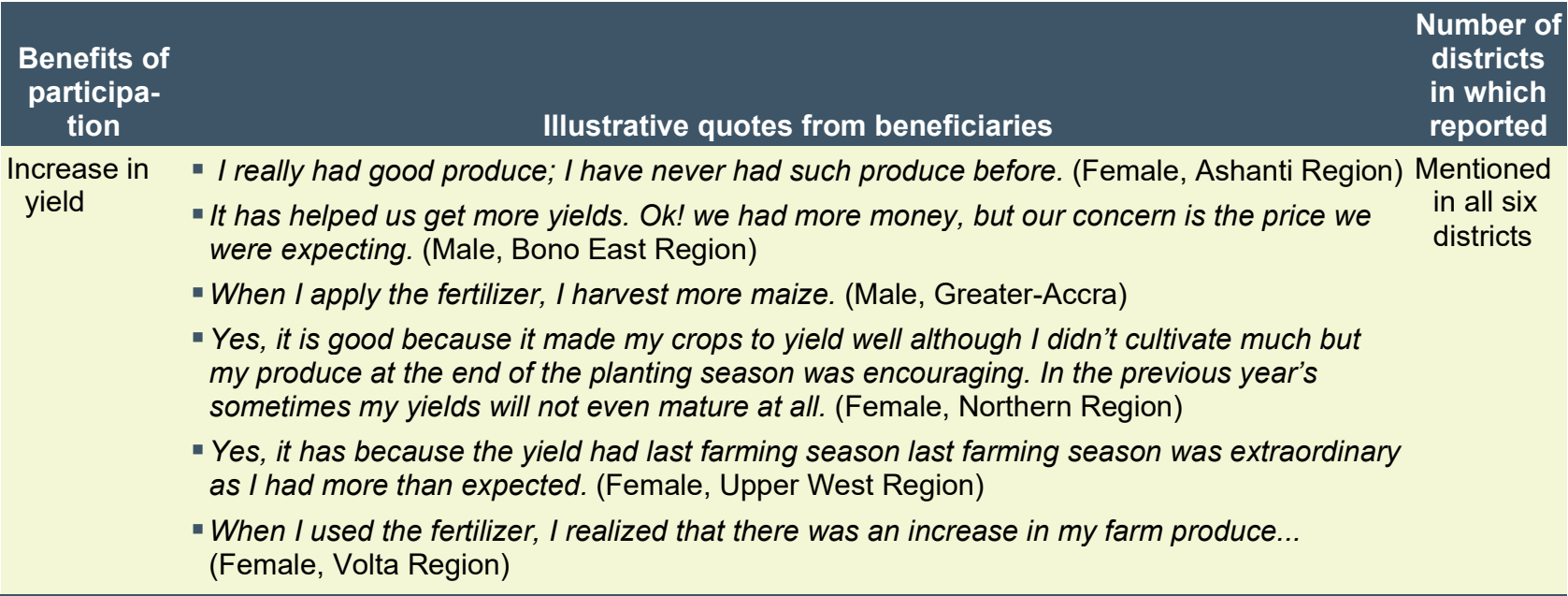


Increase in - It has also improved my income as I was able to sell most of the produce and consumed income and some. (Male, Upper West Region)

food security

- I got increased yields and increase income (Female, Volta Region)

Mentioned

in five out

of six

- Actually, the income was improved. (Male, Greater-Accra Region)

districts

- The benefits are unlimited I mentioned one earlier about helping our farm produce to mature and increasing our yield at the end of the planting season. And we are enjoying better benefits like we've been able to sell some of the produce which has increased our income level. (Male, Northern Region)

- The help I have gotten is, the price of the fertilizer was high and there were difficulties in farming, there was no money as well and even if we farm we are not able to afford the chemical so the reduction in the fertilizer has helped us. So far as the prices has been reduced, no matter what, you can afford it for your plants for some income and for that reason it has helped us. (Male, Ashanti Region)

- It has helped us in such a way that we get good yield to feed ourselves. It's mostly enough for just feeding, at least we do not buy again to feed but is not enough to sell. (Female, Northern Region)

- It has improved my income, and well secured when it comes to food (Male, Upper West Region)

- Yes, I consumed part of my farm produce at home and sold the rest. (Female, Bono-East Region) acreage

Increased - That is what I said earlier, if the fertilizer wasn't there it would have been difficult for us to cultivate and none can stand elsewhere to condemn the initiative. It has help me a lot. Previously I find it difficult to cultivate on five acres. My best was one or two acres, according to my capacity. But now if I am tilling the land, I have hope of getting some inputs. As we

Mentioned in two out of six districts speak now, there are some inputs in the store which I can have access to and apply. So, this programme from the government has been of help and my finances has increased and wherever I farm, I have inputs to support. (Male, Ashanti Region)

- It has helped the crop to yield much more than before. When I apply fertilizers, my crops do so well. Because of that, I was able to enlarge my rice farm. (Male, Volta Region)

\section{CONCLUSIONS AND PROCESS IMPROVEMENT SUGGESTIONS}

Despite the broad perception that overall the subsidized fertilizer component of the PFJ program is being implemented adequately and meeting its objectives, there were many areas highlighted for improvement from the 2019 season. This section summarizes areas of improvement mentioned in interviews with key informants and farmers.

Identify and address administrative delays in tendering: The late arrival of inputs was the challenge most mentioned by farmers, in spite of efforts to address this problem since 2018. Farmers emphasized how problematic this is, as the inputs will not provide the expected yield improvements if not applied to their crops in a timely manner. One national-level key informant mentioned that the tendering process incurs many delays due to its complexity. It should be simplified and started earlier in the season. Additionally, the online government electronic payment system, the Ghana Integrated Financial Management Information System, suffers from internet connectivity challenges that result in delays.

Another national-level respondent noted that the permitting process is often delayed due to reliance on the Minister for approval, while forms being submitted at the district level and then returned also delay aspects of the program. For example, regional- and district-level PPRSD officers manually register distributors and retailers. Similarly, registration forms are sent manually (mostly via road) to the main PPRSD office. Hard copy certificates of registration are then sent 
back to the district, which makes the process very slow. Increased use of electronic processes and forms could help reduce some of these delays. Late arrival of inputs was one of the most commonly reported issues with the 2019 PFJ implementation.

Clarify procedures and objectives/uses of listing and registration data: There were inconsistent approaches to the listing and registration process. Some districts used listings of potential beneficiaries as a mechanism to estimate (and communicate) the required quantities. Others said this was done by the input dealers themselves. If widespread adoption of the listing process would improve the efficiency of district allocation, then it should be uniformly adopted. However, the extent to which the listing data is used for this purpose is unclear from our analysis.

However, our analysis does show that inconsistencies in the registration procedures is causing confusion and some potential beneficiaries to miss out. While some districts insisted that registration with an AES or other official was a requirement to participate, others said that the streamlined process allowed farmers to go straight to the input dealer and register at the point of sale. While the latter streamlined process seems preferable, whatever procedures are put in place must be widely communicated to avoid confusion.

Clarify and communicate all targeting or exclusion criteria: Basic targeting criteria and per person limits were broadly agreed upon. However, in practice, some farmers were prioritized over others. The most common example of this was the perceived requirement that a farmer must be a member of a famer-based organization in order to receive subsidized inputs. This was a perceived requirement in five out of the six study districts, although this was not mentioned as a formal targeting requirement by any national or district-level officials.

Address inequality in input access through private sector incentives: Statements from some farming communities that PFJ was not available in their area underlines the challenge highlighted by several key informants that expansion of access to farm inputs must include explicit outreach to remote areas. One suggested that suppliers/dealers should be incentivized to set up retail shops in difficult-to-reach areas to reduce the chance that farmers living in those areas may be excluded from PFJ. However, this may not be profitable and may impose additional monitoring costs for remote shops. It is important that even those vulnerable farmers living in remote places or less well connected to their farming peers should receive explicit notification about input availability so they can avail themselves of the program before the inputs run out, as it appears, they often do. This aligns with previous research from Northern Ghana, which found that non-participants in the PFJ program spend more time traveling to input markets than participants do (Ansah, Lambongang, and Donkoh 2020). Such asymmetries in information among farmers may leave out those who would most benefit from the subsidies.

Clarify responsibility and procedures for informing farmers upon arrival of inputs: One gap in the distribution process is in the notification of farmers upon the arrival of inputs in the retail shops. There seems to be no formal process for informing farmers - most district officers described this process as word-of-mouth. However, this was described as a challenge point for many, adding time burdens and increasing expenses for farmers who must personally visit the shops to check for inputs, or miss out entirely if they do not learn about the arrival of the inputs on time. In fact, it was noted that with the private sector actors in the lead here, even the government officials are left uninformed, creating challenges of late or contradictory information being spread.

In addition, those farmers who do visit the shops and are the first to know about the arrival of subsidized fertilizer may be there because they would have been willing to purchase full priced fertilizer. This suggests a phenomenon called "crowding out", wherein the purchase of subsidized fertilizer replaced sales of fertilizer that would otherwise have happened at full price, to the 
detriment of the development of the commercial fertilizer market and national yield improvements (Jayne and Rashid 2013).

Consider narrowing targeting criteria for those who most need it: Shortages of inputs were a common complaint mentioned. In particular, shops running out of subsidized fertilizer during the growing season, low stocks in the minor season, and the per person limit were common complaints made. Others mentioned how officers limited registration because of limited supply. While it is perhaps a sign of increasing demand for fertilizer -a key benefit of fertilizer subsidies - it also points to challenges with the universal targeting approach. Farmers may plan for the use of subsidized fertilizer in a growing season and be disappointed after spending time and resources to try to acquire the subsidized inputs. In the Northern Region, other agricultural programs and service providers have reportedly felt the need to step in to supply inputs that farmers need should PFJ be unable to deliver them. A slightly narrower definition of target farmer and leveraging of other programs or support for those left out by the narrower targeting would improve the efficiency of the program and set clearer expectations on the part of farmers.

Furthermore, the crowding out phenomenon described above tends to be less when subsidy programs are targeted to relatively poor farmers and areas where the commercial demand for fertilizer is low. Thus, narrower targeting could improve the effectiveness of the program (Jayne and Rashid 2013).

Emphasize supply of inputs for minor season: In addition, there is an argument for emphasizing minor season fertilizer availability. With higher prices for produce in the minor season, the investment in fertilizer will have a greater effect on farmer incomes and support off-season food availability.

Address breakdowns in biometric data collection system: Inclusion errors - people receiving subsidized inputs who should not - and double-dipping - beneficiaries receiving more than the per person quota - are major public concerns. While there are few confirmed mentions of these problems occurring, the combination of quasi-universal targeting and insufficient tracking of beneficiaries suggests that it would be easy to do so. For instance, officials note that the biometric system was meant to identify and stop potential double-dippers. However, with the breakdown of this system, double-dipping remains easy to do. Also, pre-registration may have been a line of defense against both inclusion errors and double-dipping, but many districts are no longer doing pre-registering for the PFJ subsidized fertilizer program. Clearly there were major challenges in implementing the biometric data collection system, and the feasibility of addressing these challenges should be considered. Alternatively, requirements for pre-registration could be reinstated, or other deterrents, such as fines for double-dipping, could be put in place.

Good program modifications must be accompanied by strong communication: As the government continues to modify the PFJ subsidized fertilizer program to improve it in the face of challenges, such as the shift away from vouchers when widespread corruption was found, thought and time must be given to effectively inform people about these changes. Information sharing in program implementation has suffered given the complex nature of the program and the many actors helping to implement it in the face of changes. Providing timely updates for personnel and beneficiaries on any changes to the design of the program should be strongly emphasized. Ensuring that this information is widely disseminated is equally important to the input distribution itself. 


\section{REFERENCES}

Ansah, I.G.K., M. Lambongang, and S.A. Donkoh. 2020. "Ghana's Planting for Food and Jobs Programme: A Look at the Role of Capability in Farmers' Participation." Journal of Human Development and Capabilities 21 (2): 161-182. https://doi.org/10.1080/19452829.2020.1745162.

Birner, R., M. Cohen, and J. Ilukor. 2011. Rebuilding Agricultural Livelihoods in Post-Conflict Situations: What Are the Governance Challenges? The Case of Northern Uganda. Uganda Strategy Support Program Working Paper 07. Washington DC: International Food Policy Research Institute.

Goodrick, D. 2014. Comparative Case Studies. Methodological Briefs Impact Evaluation No. 9. Florence, Italy: UNICEF Office of Research - Innocenti.

Jayne, T.S., and S. Rashid. 2013. "Input Subsidy Programs in Sub-Saharan Africa: A Synthesis of Recent Evidence." Agricultural Economics 44 (6): 547-562. http://doi.wiley.com/10.1111/agec.12073.

Mabe, F.N., G. Danso-Abbeam, and D.S. Ehiakpor. 2018. Assessment of Implementation of Planting for Food and Jobs (PFJ) Programme: Lessons and Ways Forward. Feed the Future Ghana Agriculture Policy Support Project (APSP) Technical Paper. Accra: ASAP.

Marshall, M.N. 1996. “Sampling for Qualitative Research." Family Practice 13 (6): 522-525. http://www.ncbi.nlm.nih.gov/pubmed/9023528.

MoFA (Ministry of Food and Agriculture). 2017. Planting for Food and Jobs: Strategic plan for implementation (2017-2020). Accra: MoFA 


\section{ABOUT THE AUTHORS}

Noora-Lisa Aberman (naberman@gainhealth.org) is Senior Technical Specialist at the Global Alliance for Improved Nutrition (GAIN), based in Washington, DC. When this research was conducted, Dr. Aberman was an Associate Research Fellow in the Ghana Strategy Support Program (GSSP) of the International Food Policy Research Institute (IFPRI), based in Accra. Doreen S. Kufoalor is a Research Officer in GSSP of IFPRI, based in Accra. Rachel Gilbert is a Researcher for the Food Prices for Nutrition project at Tufts University, Boston. Ms. Gilbert was a Research Analyst with the Development Strategy and Governance Division of IFPRI, based in Washington, DC, when this research was conducted.

\section{ACKNOWLEDGMENTS}

This Working Paper is a reproduction of a joint output of the International Food Policy Research Institute (IFPRI) and the Government of Ghana through the Ministry of Food and Agriculture (MoFA) and the Ministry of Monitoring and Evaluation as part of the project "Planting for Food and Jobs Monitoring and Evaluation System" funded by the Alliance for a Green Revolution in Africa (AGRA) and its partners under the Partnership for Inclusive Agricultural Transformation in Africa (PIATA). Co-funding from the CGIAR Research Program on Policies, Institutions and Markets (PIM) as well as the International Finance Corporation (IFC) is greatly acknowledged.

We also would like to express profound gratitude to Prof. Felix Ankomah Asante (Pro-ViceChancellor for Research, Innovation, and Development, University of Ghana), Dr. Simon Bawakyillenuo, and Dr. Martha A. Awo, all from the Institute of Statistical, Social, and Economic Research (ISSER) at the University of Ghana, Legon, for their immense support and contributions during the implementation of this component of the project. We are grateful to Karl Pauw, Todd Benson, Seth Asante, and colleagues at MoFA for their reviews.

The views expressed are those of the authors and do not necessarily reflect those of their funding partners or of their employers. 